\title{
PENGEMBANGAN MEDIA PEMBELAJARAN UNTUK ANAK USIA DINI MENGGUNAKAN AUGMENTED REALITY
}

\author{
Nia Saurina \\ Program Studi Teknik Informatika, Fakultas Teknik, Universitas Wijaya Kusuma Surabaya \\ Jl. Dukuh Kupang XXV/54, Surabaya 60255, Jawa Timur, Indonesia \\ Email: niasaurina@gmail.com
}

\begin{abstract}
Learning media for early childhood is a tool to introduce themes as teaching material are often calls curriculum for early childhood. More sensing device involve at teaching and learning process, then children more understand about the lesson from their teacher. Until today learning media still use book or face to face method. While early childhood can be easily bored and more interesting in the new method. That's way the research does development in learning media to introduce animals with Augmented Reality (AR), so that children can know the type of environment and food for animal's needed. This research has case studies in Wildani 2 Surabaya Kindergaten as respondent for the test result. The test result explains that $93 \%$ of children can recognize pets as an object, as big as $100 \%$ said children can repeat the spelling of the name of the animal with Indonesian Langugage which demonstrated with augmented reality, as big as $95 \%$ of children can repeat the spelling of the name of the animal with English Language which demonstrated with augmented reality, as big as $95 \%$ of children can mention the characteristics of the animal by choosing one part of the body, and as big as 100\% said children are more interested in using AR than Viewer tool Education as learning media.
\end{abstract}

Keywords: Learning Media, Introduce Animal, Augmented Reality

\begin{abstract}
ABSTRAK
Media pembelajaran untuk anak usia dini merupakan alat bantu yang digunakan untuk mengenalkan tematema sebagai bahan ajaran atau yang sering disebut dengan kurikulum untuk anak usia dini. Semakin banyak alat indra yang terlibat dalam proses belajar maka semakin besar kemungkinan anak paham pada materi yang disampaikan oleh pengajar atau guru. Untuk saat ini media pembelajaran masih menggunakan metode tatap muka atau buku. Sedangkan anak usia dini gampang bosan dan lebih tertarik dengan hal baru. Untuk itu peneliti melakukan pengembangan media pembelajaran yang digunakan untuk mengenalkan binatang menggunakan Augmented Reality (AR), sehingga anak dapat mengetahui lingkungan hidup dan makanan yang dibutuhkan oleh binatang yang diperkenalkan tersebut. Penelitian ini mengajak anak-anak KBIT Wildani 2 Surabaya sebagai responden hasil uji coba aplikasi yang telah dibangun. Hasil uji coba menjelaskan bahwa 93\% anak dapat mengenali objek binatang dari lingkungan hidupnya, sebesar $100 \%$ menyatakan anak dapat mengulang ejaan nama dari hewan dengan Bahasa Indonesia yang diperagakan dengan augmented reality, sebesar 95\% anak dapat mengulang ejaan nama dari hewan dengan Bahasa Inggris yang diperagakan dengan augmented reality, sebesar 95\% anak dapat menyebutkan ciri-ciri binatang dengan memilih salah satu bagian tubuh dari bidanatang yag dipilih, dan sebesar $100 \%$ menyatakan anak lebih tertarik menggunakan AR daripada menggunakan Alat Peraga Edukasi (APE) sebagai media pembelajaran.
\end{abstract}

Kata kunci: Media Pembelajaran, Pengenalan Binatang, Augmented Reality

\section{PENDAHULUAN}

Sejak lahir seorang anak manusia memiliki lebih dari 100 milyar sel otak. Sel-sel otak saling berhubungan dengan sel-sel syaraf. Sel-sel otak ini dapat berkembang dengan pesat dengan adanya stimulasi pendengaran dan visualisasi untuk mengoptimalkan kerja memori otak dalam menerjemahkan setiap benda yang dikenalkan pada anak serta mengolah informasi dari benda tersebut [1]. Di sinilah perlunya pendidikan sejak usia dini yang didasarkan pada Undang-Undang Nomor 20 Tahun 2003 tentang Sistem Pendidikan Nasional, menyatakan bahwa pendidikan anak usia dini adalah salah satu upaya pembinaan 
yang ditujukan untuk anak sejak lahir sampai dengan 6 tahun yang dilakukan melalui pemberian rangsangan pendidikan untuk membantu pertumbuhan dan perkembangan jasmani dan rohani agar anak memiliki kesiapan dalam memasuki jenjang pendidikan lebih lanjut [2].

Pendidikan anak pada usia 2-4 tahun masuk pada Kelompok Bermain (KB) dimana anak berusaha menguasai simbol-simbol (kata-kata) dan mampu mengungkapkan pengalamannya, meskipun tidak logis (pra-logis). Pada saat ini anak bersifat egosentris, yaitu melihat sesuatu dari dirinya (perception centration), dengan melihat sesuatu dari satu ciri, sedangkan ciri lainnya diabaikan [3]. Selain itu anak pada usia 2-4 tahun memiliki kemampuan untuk mengikuti aturan permainan termasuk memahami tujuan dari permainan yang diberikan kepadanya [4].

Binatang merupakan mahluk yang menarik bagi anak - anak karena mampu merespon rangsang. Meskipun masih diperdebatkan dari segi sanitasi dan higienisnya, memelihara binatang sebagai hewan peliharaan dapat mengembangkan rasa kasih dan sayang pada anak. Melalui hewan peliharaan anak dapat belajar banyak tentang mahluk tersebut. Oleh karena itu di nagara-negara maju, kebun binatang dilengkapi dengan pojok sains (sains center) dimana anak dapat berinteraksi dengan bintang yang jinak dan bersih sambil mempelajarinya. Ada beberapa keuntungan yang diperoleh anak pada saat berinteraksi dengan binatang. Pertama, anak belajar mengenal dan menghargai mahluk hidup, ia belajar bahwa mahluk hidup memerlukan makanan, tempat tinggal dan kasih sayang. Kedua, anak belajar untuk menyayangi binatang yang pada akhirnya dapat menumbuhkan rasa kasih sayang pada mahluk hidup [5].

Augmented Reality (AR) merupakan sintesis perumpamaan nyata dan virtual [6]. Aplikasi AR telah diterapkan di berbagai bidang kehidupan, dimana AR dijadikan sebagai konsep aplikasi yang menggabungkan dunia fisik (objek sesungguhnya) dengan dunia digital, tanpa mengubah bentuk objek fisik tersebut. Pengenalan objek (teks dan gambar) yang digunakan untuk menampilkan berbagai informasi mengenai objek tersebut. Augmented reality sebagai sebuah sistem kognitif dan mampu memahami secara utuh persepsi dari pengguna [7].

Penelitian ini bertujuan untuk mengembangkan media pembelajaran dengan memanfaatkan teknologi Augmented Reality sehingga proses belajar mengajar lebih menarik dikarenakan dapat menampilkan objek tiga dimensi yang dapat menyerupai bentuk aslinya. Media pembelajaran pada penelitian ini ditujukan kepada anak usia dini yang bergabung pada KB sehingga anak dapat melihat, melafalkan, menyentuh dengan tujuan merubah ukuran objek serta dapat melakukan perputaran terhadap objek yang ditampilkan. Penelitian ini melibatkan KBIT Wildani 2 Surabaya yang bertempat di Ketintang Barat I No. 27 Surabaya untuk melakukan uji coba kepuasan pengguna dengan menggunakan indikator keberhasilan diantaranya: kemampuan anak untuk dapat mengenali objek binatang dari lingkungan hidupnya, kemampuan anak dapat menyebutkan nama binatang dari objek yang ditampilkan, ketertarikan anak dalam menggunakan AR dibandingkan dengan menggunakan Alat Peraga Edukasi (APE) dan kepuasan anak terhadap tampilan objek terhadap sentuhan pengguna, dimana anak dapat menyentuh objek dengan tujuan merubah ukuran objek dan memutar objek sebesar $360^{\circ}$.

\section{TINJAUAN PUSTAKA}

\section{Anak Usia Dini}

Anak adalah individu yang unik dimana ia memiliki pola pertumbuhan dan perkembangan dalam aspek fisik, kognitif, sosio emosional, kreativitas, bahasa dan komunikasi yang khusus yang sesuai dengan tahapan yang sedang dilalui oleh anak tersebut. 
Masa anak usia dini sering disebut dengan istilah "golden age" atau masa emas. Pada masa ini hampir seluruh potensi anak mengalami masa peka untuk tumbuh dan berkembang secara cepat dan hebat. Perkembangan setiap anak tidak sama karena setiap individu memiliki perkembangan yang berbeda. Makanan yang bergizi dan seimbang serta stimulasi yang intensif sangat dibutuhkan untuk pertumbuhan dan perkembangan tersebut. Apabila anak diberikan stimulasi secara intensif dari lingkungannya, maka anak mampu menjalani tugas perkembangannya dengan baik. Karakteristik yang dilalui anak usia 2-4 tahun antara lain: 1) anak sangat aktif untuk mengeksplorasi benda-benda yang ada di sekitarnya. Eksplorasi yang dilakukan anak terhadap benda yang ditemui merupakan proses belajar yang sangat efektif, 2) anak mulai belajar mengembangkan kemampuan berbahasa yaitu dengan berceloteh. Anak belajar berkomunikasi, memahami pembicaraan orang lain dan belajar mengungkapkan isi hati dan pikiran, 3) anak belajar mengembangkan emosi yang didasarkan pada faktor lingkungan karena emosi lebih banyak ditemui pada lingkungan (3)

\section{Augmented Reality}

Augmented Reality merupakan konsep penggabungan dunia virtual ke dalam dunia nyata. Penciptaan dunia virtual dilakukan untuk membangkitkan persepsi pengguna untuk memahami informasi dari objek yang dikenali. Augmented Reality didefinisikan sebagai penggunaan komputer digital real-time dan perangkat keras spesial lainnya dan perangkat lunak untuk menghasilkan sebuah simulasi dunia atau lingkungan alternative, yang dipercaya sebagai sesuatu yang nyata atau benar bagi pengguna [8]. Terdapat dua metode pengenalan penanda pada augmented reality, yaitu; marker dan markerless. Marker merupakan penanda khusus yang dibuat seperti sebuah barcode atau bingkai hitam, sedangkan markerless merupakan penanda yang berhubungan dengan objek secara langsung. Adapun evolusi dari penggunaan marker hingga penggunaan objek nyata dalam pengenalan penanda augmented reality seperti ditunjukkan pada Gambar. 1 .

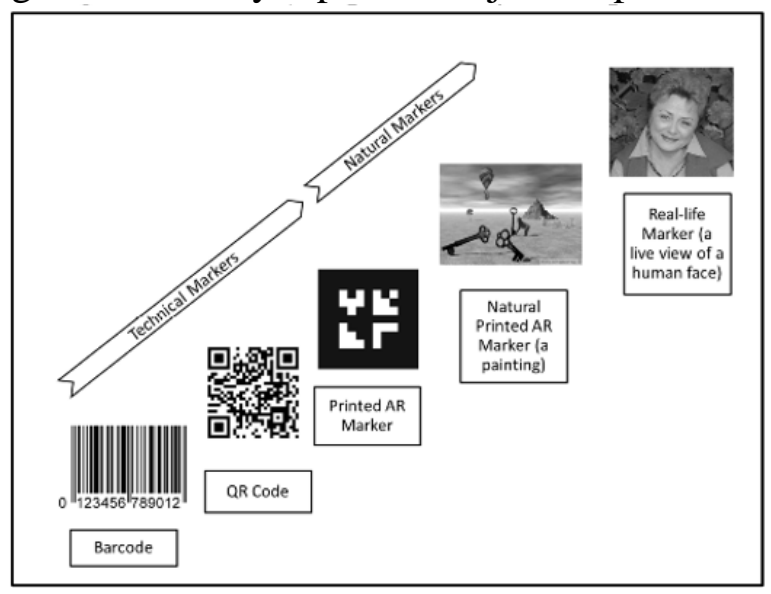

Gambar 1. Evolusi Marker.

Evolusi penanda ditunjukkan dengan perubahan penanda yang dimulai dari bentuk barcode hingga bentuk nyata di kehidupan (real life). Penanda diklasifikasikan menjadi dua, yaitu; marker dan markerless. Evolusi penanda yang termasuk di dalam klasifikasi marker atau yang dikenal sebagai technical markers, yaitu; barcode, QR code, dan printed AR marker. Sedangkan yang termasuk ke dalam markerless (natural markers), yaitu; natural printed AR marker dan real life marker [9]. Penelitian ini menjelaskan penerapan penggunaan marker berupa natural printed AR marker sebagai penanda yang diterapkan pada perancangan aplikasi AR. File tersebut disimpan dalam format digital berupa; *.jpg, *.jpeg, *.png, *.bmp, *.gif, sedangkan pengenalan dengan metode object tracking dan 
environment tracking berupa pengenalan objek 3D. Objek 3D yang dapat dikenali terlebih dahulu dirancang modelnya yang kemudian disimpan dalam format *.FBX dan *.BLEND.

\section{Augmented Reality dan Anak Usia Dini}

Saat ini augmented reality menjadi teknologi yang cukup diminati. Penelitian ini ditujukan pada anak usia dini untuk membantu mereka mengenali konten pembelajaran dan lebih cepat memahami materi yang diberikan. Augmented reality merupakan konsep yang cukup pintar dikarenakan anak belajar menggunakan imajinasi. Anak mendapatkan materi sambal menambah pengalaman dan menyentuh objek pada dunia nyata [10].

Penggunaan Augmented Reality yang ditujukan kepada anak usia dini telah dikembangkan oleh beberapa peneliti diantaranya adalah penelitian yang dilakukan oleh Rasslenda-Rass [11] yang menghasilkan tingkat ketertarikan dan motivasi anak menggunakan augmented reality dibandingkan pembelajaran secara konvensional. Penelitian ini menghasilkan AR Flashcard yang didesain untuk aplikasi iOS. AR Flashcard melibatkan simulasi dan interaksi pengenalan binatang menggunakan virtual 3D. Selain itu penggunaan Augmented Reality telah dikembangkan oleh Azfar [12] dengan memanfaatkan augmented reality dengan memvisualisasikan dongeng Thristy Crow untuk menghitung jumlah Burung Gagak yang terdapat di buku cerita.

\section{METODE}

\section{Kebutuhan Pengguna}

Kebutuhan pengguna disesuaikan dengan kurikulum yang digunakan KBIT Wildani 2 Surabaya, sehingga memunculkan objek binatang secara 3D dan dapat mendukung keberhasilan proses pembelajaran yang telah dilaksanakan di KBIT tersebut. Jenis Binatang yang diperkenalkan pada KBIT Wildani 2 Surabaya adalah binatang kesayangan; binatang darat, air/laut, terbang; binatang buas, serangga; binatang yang melompat, merayap, memanjat/bergelantungan; binatang yang bertelur dan beranak; binatang yang berbulu, bertanduk; tempat tinggal binatang; ciri-ciri binatang

Beberapa tujuan pembelajaran yang perlu diperhatikan dalam menampilkan objek binatang secara 3D diantaranya:

1. Anak didik dapat menyebutkan nama binatang

2. Anak didik dapat menyebutkan lingkungan tempat hidup binatang

3. Anak didik dapat menceritakan kembali tentang ciri-ciri binatang yang didengar dan dilihatnya secara sederhana

\section{Kebutuhan Sistem}

Perangkat keras yang dibutuhkan untuk mendukung penelitian ini adalah:

1. Laptop dengan Spesifikasi:

Processor Core i3

Ram $2 G B$

Hard Disk 320GB

2. Smartphone LENOVO A328 dengan sistem operasi Android OS, v5.1 Kitkat

\section{Perancangan Marker Augmented Reality}

Penelitian ini menggunakan gambar fisik yang didesain sendiri oleh peneliti dengan menggunakan Adobe Photoshop sebagai natural printed AR marker. Gambar fisik tersebut digunakan sebagai objek yang dikenali oleh sistem dan disimpan ke dalam AR Store menggunakan Blender 2.76, dengan ukuran 3000px x 2000px dan menggunakan format JPEG. Penanda berupa gambar pengenalan binatang menggunakan printer dengan resolusi 
cetakan maksimum 5760dpl. Gambar dengan ukuran 1028px x 1954px menghasilkan cetakan yang melebihi ukuran kertas A5, sehingga dilakukan pengecilan gambar sebesar $25 \%$ dari gambar asli untuk mendapatkan cetakan yang dapat dimuat pada kertas berukuran A5.

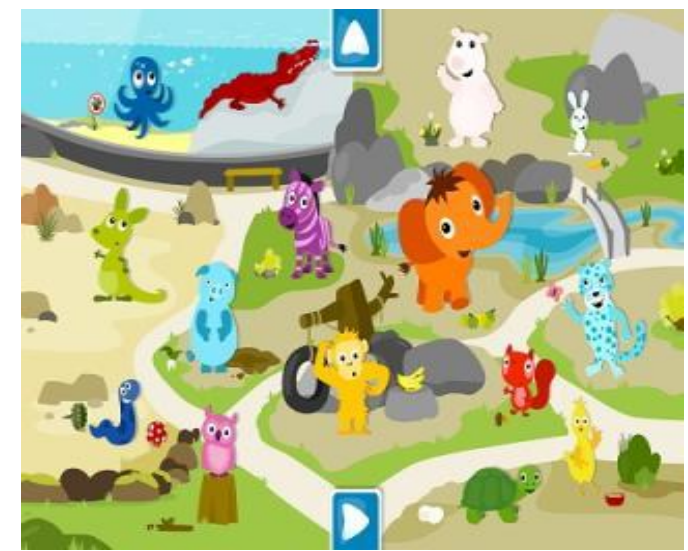

Gambar 2 Penanda Marker

\section{Perancangan Aplikasi Augmented Reality}

Proses perancangan aplikasi AR menggunakan software Unity 5.3. Proses perancangan digambarkan pada flowchart Gambar 3. Tahapan pertama dimulai dengan pemilihan model penanda (trackables). Model penanda terbagi kedalam 3 bentuk pelacakan, yaitu; image tracking, object tracking dan environment tracking. Kemudian penanda yang telah dipilih kemudian dilakukan rendering atau penyatuan gambar dengan environment yang kemudian disimpan ke dalam AR Store. Proses berikutnya yaitu proses menampilkan object 3D.

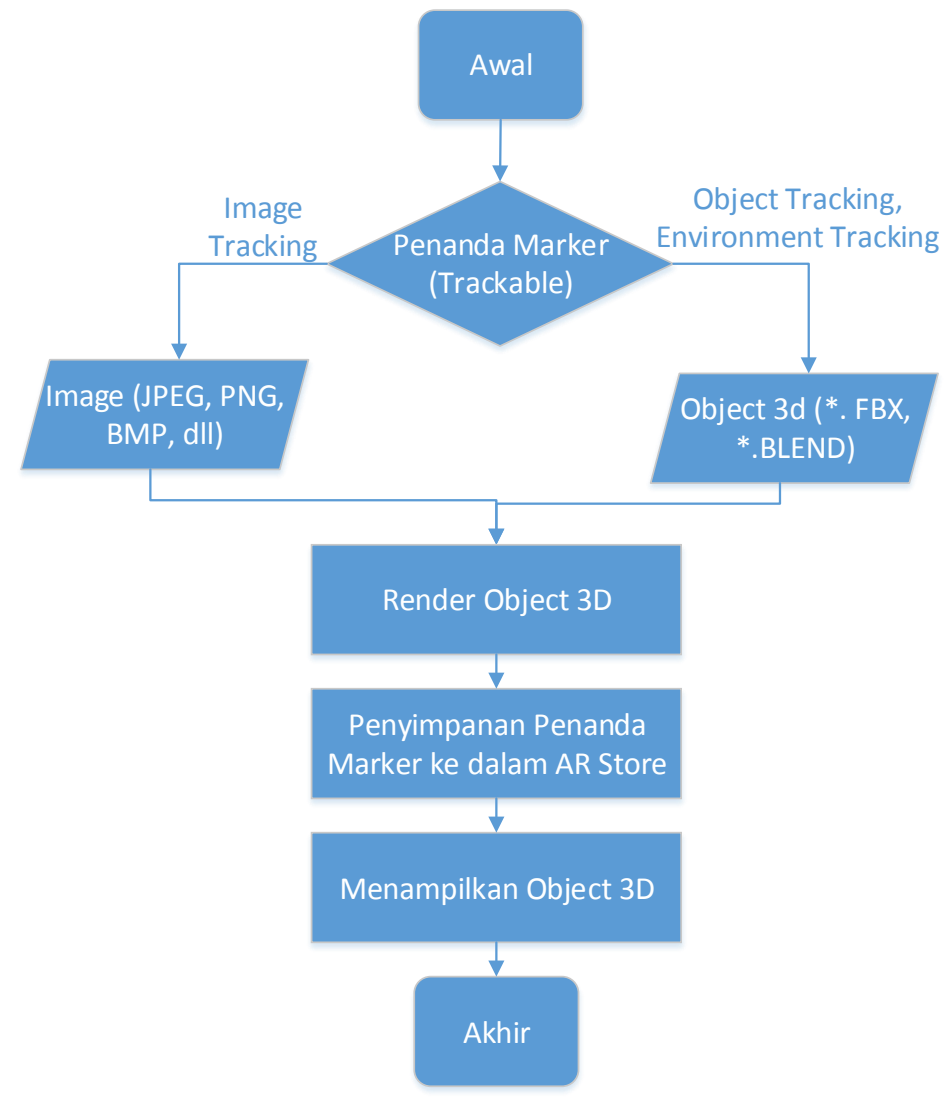

Gambar 3 Alur Kerja Perancangan Aplikasi AR 


\section{Desain Use Case Diagram}

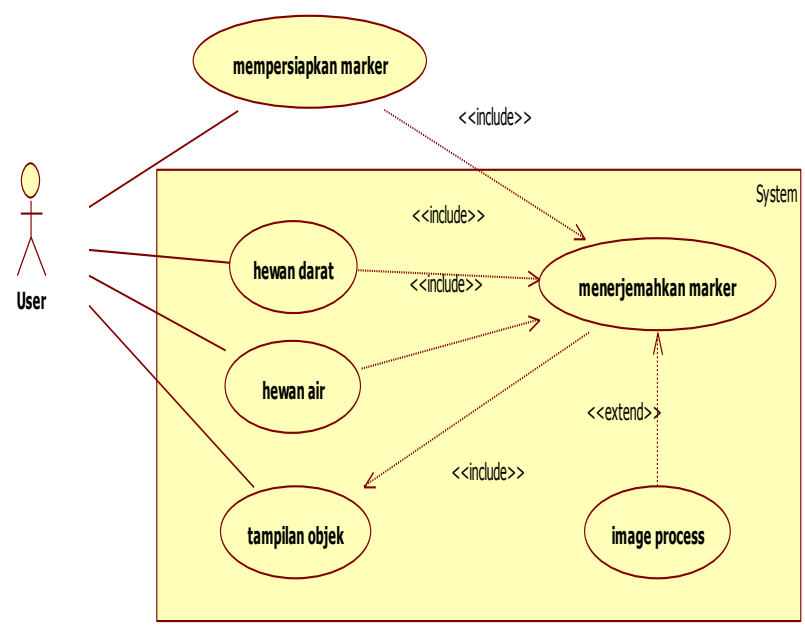

Gambar 4. Use Case Diagram

Gambar 4 menunjukkan desain use case diagram dalam pembuatan media pembelajaran. Pengguna setelah mempersiapkan marker, maka objek binatang dapat muncul di LENOVO A328. Kemudian pengguna memilih jenis tempat hidup binatang, yaitu di darat dan di air. Setelah itu maka marker dapat menerjemahkan sesuai dengan objek yang dipilih pengguna.

\section{Desain Antarmuka AR Pengenalan Binatang Berdasarkan Tempat Hidupnya Desain Antarmuka Main menu}

Tabel 1 menjelaskan desain antarmuka pada menu utama. Terdapat tiga tombol untuk memilih binatang berdasarkan tempat hidupnya. Saat pengguna memilih menu "Hewan Darat". maka aplikasi menampilkan hewan darat. Begitu pula halnya dengan saat pengguna memilih menu "Hewan Air", maka aplikasi menampilkan hewan air.

Tabel 1. Desain Antarmuka Main Menu

\begin{tabular}{|c|c|}
\hline Tampilan & Keterangan \\
\hline$\bullet$ & $\begin{array}{l}\text { Tampilan main menu pengenalan hewan: } \\
\text { - Tombol hewan darat adalah menampilkan beberapa hewan darat } \\
\text { yang dikenalkan } \\
\text { - Tombol hewan air adalah menampilkan hewan air yang dikenalka } \\
\text { - Tombol X berfungsi untuk keluar dari aplikasi }\end{array}$ \\
\hline
\end{tabular}

\section{Tampilan Menu Hewan Darat}

Tabel 2 menjelaskan desain antarmuka pada menu "Hewan Darat". Terdapat lima binatang yang diperkenalkan kepada pengguna yaitu ayam, kuda, gajah, zebra dan sapi. Saat pengguna memilih Tombol "Ayam", maka aplikasi menampilkan gambar ayam secara 3D. Hal yang serupa pada saat pengguna memilih tombol "Kuda", "Gajah", "Zebra" dan "Sapi". Dan pada saat pengguna menekan bagian tubuh dari binatang yang telah ditampilkan, maka aplikasi mengeluarkan suara dengan menyebutkan nama bagian tubuh dari binatang tersebut.

Tabel 2. Menu Hewan Darat

Tampilan $\quad$ Keterangan




\begin{tabular}{|l|l|}
\hline & $\begin{array}{l}\text { Tampilan main menu Hewan Darat: } \\
\text { - Tombol Ayam berfungsi untuk masuk ke sceen tampilan 3D } \\
\text { ayam } \\
\text { - Tombol Kuda berfungsi untuk masuk ke sceen tampilan 3D } \\
\text { kuda } \\
\text { - Tombol Gajah berfungsi untuk masuk ke sceen tampilan 3D } \\
\text { gajah } \\
\text { - Tombol Zebra berfungsi untuk masuk ke sceen tampilan 3D } \\
\text { zebra } \\
\text { - Tombol Sapi berfungsi untuk masuk ke sceen tampilan 3D } \\
\text { sapi } \\
\text { - Tomboß berfungsi untuk kembali ke main menu utama } \\
\text { - Tombol X berfungsi untuk keluar dari aplikasi }\end{array}$ \\
\end{tabular}

\section{Tampilan Menu Hewan Air}

Tabel 3 menjelaskan desain antarmuka pada menu "Hewan Air". Terdapat lima binatang yang diperkenalkan kepada pengguna yaitu ikan paus, bintang laut, ikan lumba-lumba, ikan hiu dan ikan koki. Saat pengguna memilih Tombol "Ikan Paus", maka aplikasi menampilkan gambar ikan paus secara 3D. Hal yang serupa pada saat pengguna memilih tombol "bintang laut", "ikan lumba-lumba", "ikan hiu" dan "ikan koki". Dan pada saat pengguna menekan bagian tubuh dari binatang yang telah ditampilkan, maka aplikasi mengeluarkan suara dengan menyebutkan nama bagian tubuh dari binatang tersebut.

Tabel 3. Menu Hewan Air

\begin{tabular}{|c|c|}
\hline Tampilan & Keterangan \\
\hline 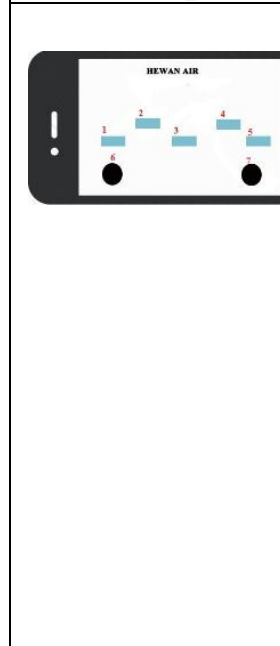 & $\begin{array}{l}\text { - Tampilan main menu Hewan Air: } \\
\text { - Tombol Ikan Paus berfungsi untuk masuk ke sceen tampilan 3D } \\
\text { Ikan paus } \\
\text { - Tombol Bintang Laut berfungsi untuk masuk ke sceen tampilan } \\
\text { 3D bintang laut } \\
\text { - Tombol Ikan Lumba-Lumba berfungsi untuk masuk ke sceen } \\
\text { tampilan 3D Ikan lumba-lumba } \\
\text { - Tombol Ikan Hiu berfungsi untuk masuk ke sceen tampilan 3D } \\
\text { Ikan Hiu } \\
\text { - Tombol Ikan Koki berfungsi untuk masuk ke sceen tampilan 3D } \\
\text { Ikan badut } \\
\text { - Tomboß berfungsi untuk kembali ke main menu utama } \\
\text { - Tombol X berfungsi untuk keluar dari aplikasi }\end{array}$ \\
\hline
\end{tabular}

\section{Tampilan Objek 3D}

Tabel 4 menjelaskan desain tata letak aplikasi untuk menampilkan objek binatang. Terdapat tombol "Sound" agar aplikasi dapat mengeluarkan suara nama binatang yang dipilih pengguna. Tombol "Bahasa Indonesia" agar aplikasi dapat mengeluarkan suara untuk menyebutkan nama binatang dalam Bahasa Indonesia, hal yang sama pada saat pengguna memilih tombol "Bahasa Inggris", maka aplikasi dapat mengeluarkan suara dengan menyebutkan nama binatang dalam Bahasa Inggris. 
Tabel 4. Tampilan Objek 3D

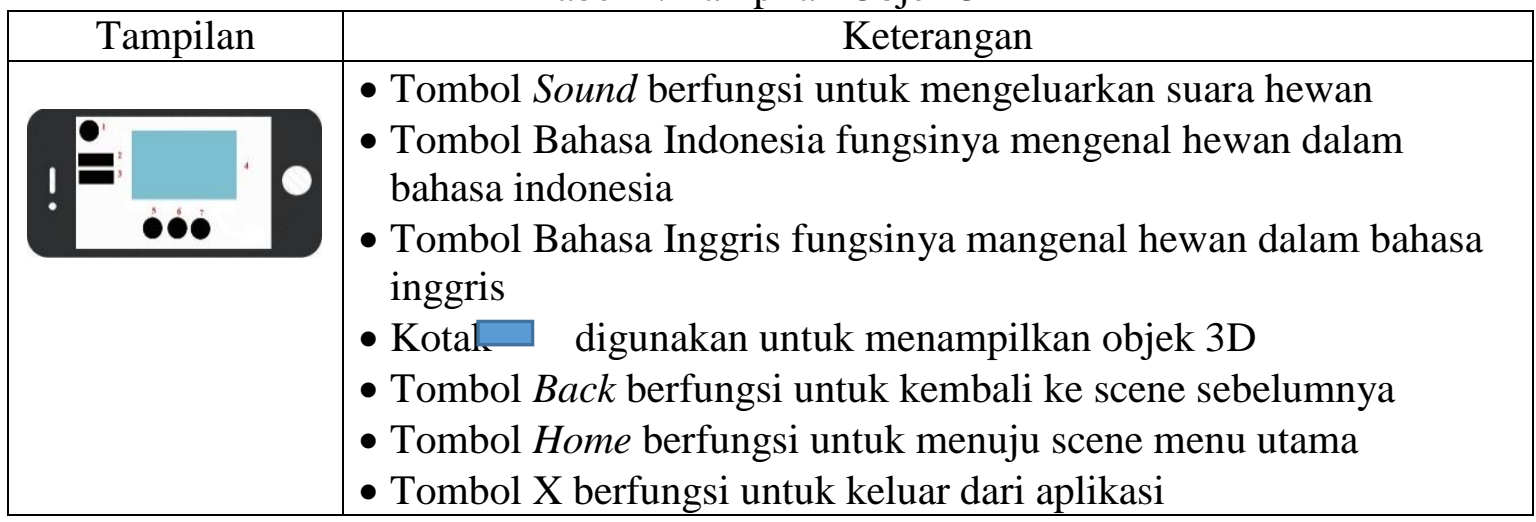

\section{IMPLEMENTASI DAN UJICOBA}

Implementasi Desain Antarmuka

\section{Tampilan Main Menu}

Gambar 5 menunjukkan tampilan menu utama saat pengguna membuka aplikasi media pembelajaran. Terdapat dua tombol utama yaitu tombol kumpulan hewan darat dan kumpulan hewan air.

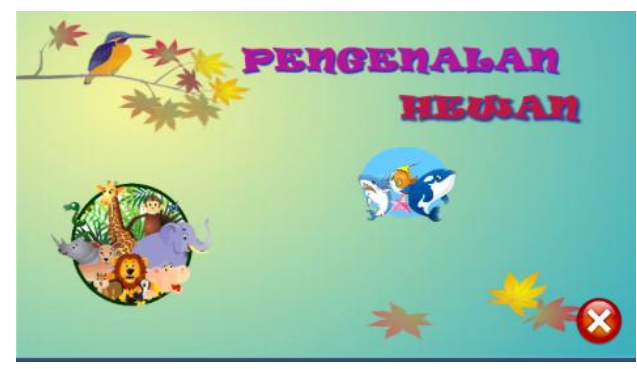

Gambar 5. Tampilan Main Menu

\section{Tampilan Menu Hewan Darat}

Gambar 6 menunjukkan tampilan menu "Hewan Darat". Terdapat lima binatang yang dapat dipilih pengguna yaitu ayam, kuda, gajah, zebra dan sapi.

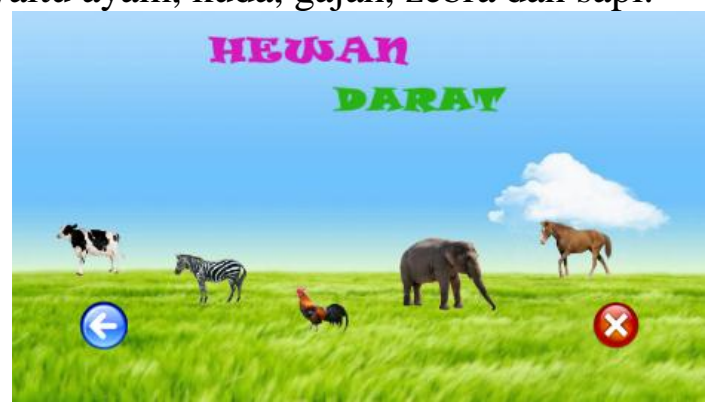

Gambar 6. Tampilan Hewan Darat

Tampilan Menu Hewan Air 
Gambar 7 menunjukkan tampilan menu "Hewan Air". Terdapat lima binatang yang dapat dipilih pengguna yaitu ikan paus, bintang laut, ikan lumba-lumba, ikan hiu dan ikan koki.

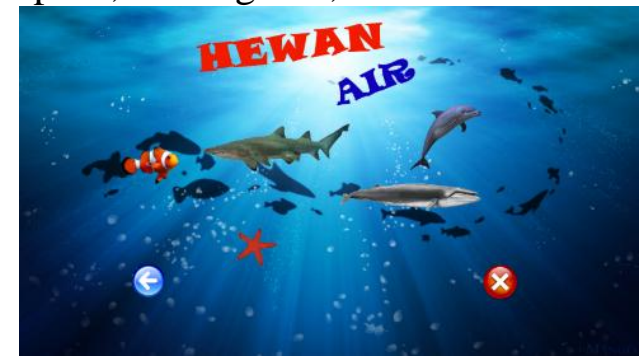

Gambar 7. Tampilan Menu Hewan Air

\section{Tampilan Scene AR}

Gambar 8 menunjukkan tampilan layar atau scene pada saat aplikasi mendeteksi belum adanya marker.

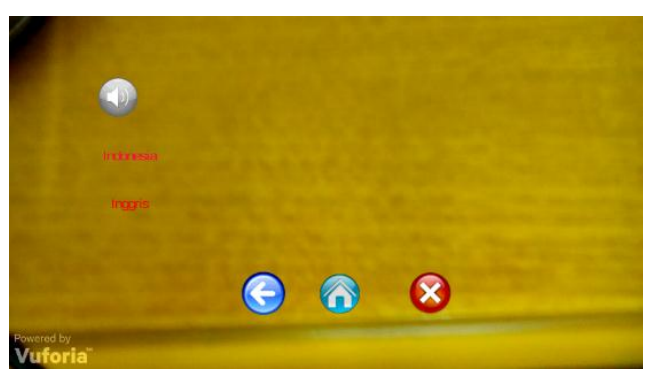

Gambar 8. Scene AR

\section{Ujicoba Aplikasi}

Pengujian yang dilakukan terhadap sistem adalah pengujian fungsi dari Button dan AR. Ujicoba aplikasi menggunakan Smartphone LENOVO A328 dengan Spesifikasi, Ram 1 Gb, Android Kitkat, Camera 5 Mega Pixel. Pada ujicoba AR, camera smartphone diarahkan ke marker, setelah marker ter-identifikasi, maka aplikasi menampilkan objek binatang secara 3D. Saat button INDONESIA di klik maka terdengar sound dengan Bahasa Indonesia, saat button ENGLISH di klik maka terdengar sound nama objek dengan Bahasa Inggris, saat button Home (gambar rumah) maka tampilan kembali ke menu utama, saat button sound (gambar sound) di klik maka terdengar suara hewan pada objek, saat button X maka pengguna keluar dari aplikasi, dan saat button <- maka pengguna dapat kembali ke scene sebelumnya. Gambar 9 menunjukkan objek Gajah saat aplikasi mendeteksi adanya marker. Objek yang tampil berupa visualisasi secara 3 dimensi, sehingga anak dapat melihat objek dari segala sisi. Walaupun anak memutari objek, anak tetap dapat melihat wujud objek dengan jelas. Bentuk dan warna yang tampil pada objek gajah disesuaikan dengan bentuk dan warna aslinya, hanya saja ukurannya lebih kecil daripada aslinya. Dengan melihat objek gajah melalui $\mathrm{AR}$, anak dapat menyebutkan nama binatang dari ciri-ciri objek yang dikeluarkan. Ciri-ciri dari gajah adalah memiliki hidung yang panjang dan telinga yang lebar. Selain itu anak dapat menyebutkan lingkungan tempat hidupnya yaitu gajah hidup di darat dan makanannya adalah rumput. Media pembelajaran ini juga menampilkan 2 bahasa yaitu Bahasa Indonesia dan Bahasa Ingrris, sehingga pada saat objek yang keluar adalah gajah, maka anak dapat mendengarkan suara 'elephant' untuk mengenalkan nama binatang yang ditampilkan AR dengan Bahasa Ingrris. 


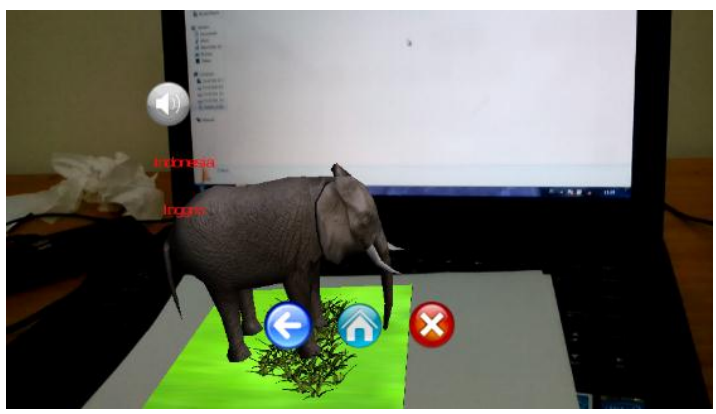

Gambar 9. Hasil ujicoba AR gajah

Gambar 10 menunjukkan objek Ayam saat aplikasi mendeteksi adanya marker. Objek yang tampil berupa visualisasi secara 3 dimensi, sehingga anak dapat melihat objek dari segala sisi. Walaupun anak memutari objek, anak tetap dapat melihat wujud objek dengan jelas. Bentuk dan warna yang tampil pada objek ayam disesuaikan dengan bentuk dan warna aslinya, hanya saja ukurannya lebih kecil daripada aslinya. Dengan memunculkan objek ayam, maka anak dapat mengenali objek yang dikeluarkan dari AR berdasarkan ciriciri yang dimiliki. Ayam memiliki ciri-ciri adalah memiliki paruh yang tebal dan panjang, memiliki kaki dua dan kakinya bertanduk. Selain itu anak dapat menyebutkan jenis lingkungan hidupnya ayam yaitu di darat dan memakan biji-bijian, beserta nama binatang menggunakan Bahasa Inggris yaitu 'rooster'

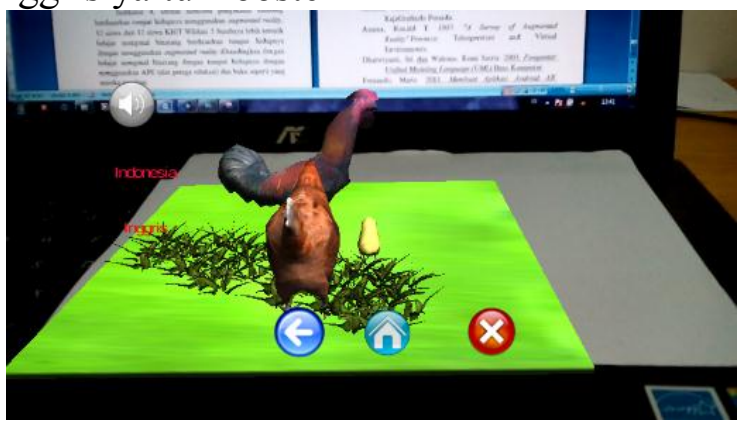

Gambar 10. Ujicoba AR Ayam

Gambar 11 menunjukkan objek Bintang Laut saat aplikasi mendeteksi adanya marker. Objek yang tampil berupa visualisasi secara 3 dimensi, sehingga anak dapat melihat objek dari segala sisi. Walaupun anak memutari objek, anak tetap dapat melihat wujud objek dengan jelas. Bentuk dan warna yang tampil pada objek Bintang Laut disesuaikan dengan bentuk dan warna aslinya, hanya saja ukurannya lebih kecil daripada aslinya. Anak-anak dapat menyebutkan bintang laut dari ciri-ciri yang dimilikinya yaitu memiliki tangan berjumlah lima, seperti bintang dan hidup di air. Lingkungan perairan digambarkan berupa garis yang berombak dan memiliki warna biru, beserta suara deburan air yang dapat dikeluarkan oleh AR. Selain itu saat AR menampilkan Bintang laut, maka anak dapat mendengarkan 'starfish' sebagai nama Bintang Laut dalam Bahasa Inggris.

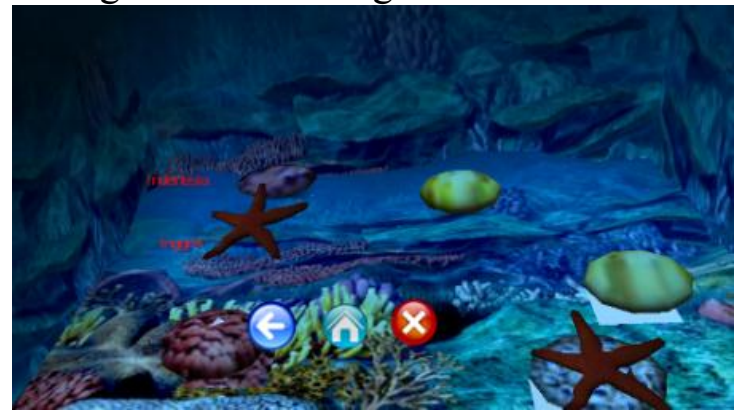




\section{Gambar 11. Ujicoba AR Bintang Laut}

Gambar 12 menunjukkan objek Ikan Hiu saat aplikasi mendeteksi adanya marker. Objek yang tampil berupa visualisasi secara 3 dimensi, sehingga anak dapat melihat objek dari segala sisi. Walaupun anak memutari objek, anak tetap dapat melihat wujud objek dengan jelas. Bentuk dan warna yang tampil pada objek Ikan Hiu disesuaikan dengan bentuk dan warna aslinya, hanya saja ukurannya lebih kecil daripada aslinya. Anak dapat mengenali ikan hiu berdasarkan ciri-ciri yang dimilikinya yaitu memiliki sirip yang panjang, memiliki sirip, memiliki memiliki mulut yang panjang, dan bergigi tajam. Lingkungan perairan digambarkan berupa garis yang berombak dan memiliki warna biru, beserta suara deburan air yang dapat dikeluarkan oleh AR. Selain itu saat AR menampilkan Ikan Hiu, maka anak dapat mendengarkan 'shark' sebagai nama Ikan Hiu dalam Bahasa Inggris.

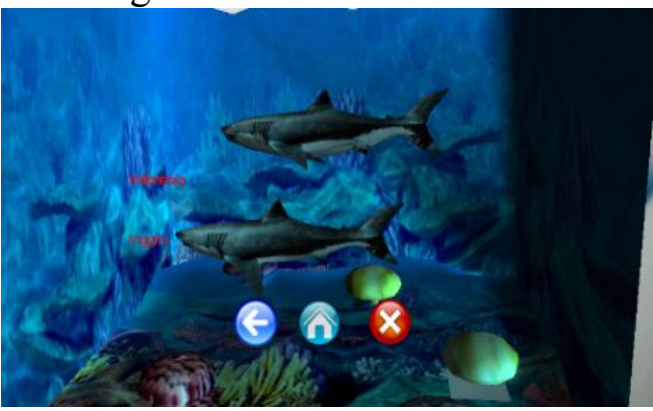

Gambar 12. Ujicoba AR Ikan Hiu

\section{Ujicoba Aplikasi pada Anak Usia Dini}

Media pembelajaran berupa pengenalan Binatang berdasarkan tempat hidupnya Augmented Reality, telah diujicobakan pada anak usia dini di KB Islam Terpadu Wildani 2 Surabaya sebanyak 12 anak. Tabel 5 menunjukkan hasil ujicoba aplikasi untuk mengukur tingkat keberhasilan pembuatan objek binatang secara 3D, bertujuan untuk mengenalkan Hewan yang hidup di darat kepada anak.

Tabel 5. Hasil Ujicoba media pembelajaran terhadap pengenalan Hewan Darat

\begin{tabular}{|c|c|c|c|}
\hline No & INDIKATOR & \multicolumn{2}{|c|}{ Jumlah Anak } \\
\hline \multirow[t]{7}{*}{1.} & \multicolumn{3}{|c|}{ Jumlah Anak yang bisa mengenali binatang dan tempat hidupnya } \\
\hline & Nama Binatang & Bisa & Tidak Bisa \\
\hline & Ayam & 12 & 0 \\
\hline & Zebra & 12 & 0 \\
\hline & Gajah & 12 & 0 \\
\hline & Sapi & 8 & 4 \\
\hline & Kuda & 12 & 0 \\
\hline \multirow[t]{7}{*}{2.} & \multicolumn{3}{|c|}{$\begin{array}{c}\text { Jumlah Anak yang bisa mengulang ejaan nama dari hewan dengan Bahasa Indonesia } \\
\text { yang diperagakan dengan augmented reality }\end{array}$} \\
\hline & Nama Binatang & Bisa & Tidak Bisa \\
\hline & Ayam & 12 & 0 \\
\hline & Zebra & 12 & 0 \\
\hline & Gajah & 12 & 0 \\
\hline & Sapi & 12 & 0 \\
\hline & Kuda & 12 & 0 \\
\hline \multirow[t]{2}{*}{3.} & \multicolumn{3}{|c|}{$\begin{array}{c}\text { Jumlah Anak yang bisa mengulang ejaan nama dari hewan dengan Bahasa Inggris } \\
\text { yang diperagakan dengan augmented reality }\end{array}$} \\
\hline & Nama Binatang & Bisa & Tidak Bisa \\
\hline
\end{tabular}




\begin{tabular}{|c|c|c|c|}
\hline No & INDIKATOR & \multicolumn{2}{c|}{ Jumlah Anak } \\
\hline \multirow{4}{*}{} & Ayam & 12 & 0 \\
\cline { 2 - 4 } & Zebra & 12 & 0 \\
\cline { 2 - 4 } & Gajah & 12 & 0 \\
\cline { 2 - 4 } & Sapi & 12 & 0 \\
\hline \multirow{4}{*}{4} & Kuda & 10 & 2 \\
\cline { 2 - 4 } & Jumlah Anak yang dapat menyebutkan ciri-ciri binatang dengan memilih salah satu \\
bagian tubuh dari binatang yang dipilih, dengan tujuan agar objek dapat mengeluarkan
\end{tabular}

Tabel 6 menunjukkan hasil ujicoba aplikasi untuk mengukur tingkat keberhasilan pembuatan objek binatang secara 3D, bertujuan untuk mengenalkan Hewan yang hidup di air kepada anak.

Tabel 6 Hasil Ujicoba media pembelajaran terhadap pengenalan Hewan Air.

\begin{tabular}{|c|c|c|c|}
\hline No & INDIKATOR & \multicolumn{2}{|c|}{ Jumlah Anak } \\
\hline \multirow[t]{7}{*}{1.} & \multicolumn{3}{|c|}{ Jumlah Anak yang bisa mengenali binatang dan tempat hidupnya } \\
\hline & Nama Binatang & Bisa & Tidak Bisa \\
\hline & Ikan Paus & 12 & 0 \\
\hline & Ikan Hiu & 12 & 0 \\
\hline & Ikan Koki & 8 & 4 \\
\hline & Lumba-lumba & 12 & 0 \\
\hline & Bintang Laut & 12 & 0 \\
\hline \multirow{7}{*}{2.} & \multicolumn{3}{|c|}{$\begin{array}{c}\text { Jumlah Anak yang bisa mengulang ejaan nama dari hewan dengan Bahasa Indonesia } \\
\text { yang diperagakan dengan augmented reality }\end{array}$} \\
\hline & Nama Binatang & Bisa & Tidak Bisa \\
\hline & Ikan Paus & 12 & 0 \\
\hline & Ikan Hiu & 12 & 0 \\
\hline & Ikan Koki & 12 & 0 \\
\hline & Lumba-lumba & 12 & 0 \\
\hline & Bintang Laut & 12 & 0 \\
\hline \multirow[t]{4}{*}{3.} & \multicolumn{3}{|c|}{$\begin{array}{c}\text { Jumlah Anak yang bisa mengulang ejaan nama dari hewan dengan Bahasa Inggris } \\
\text { yang diperagakan dengan augmented reality }\end{array}$} \\
\hline & Nama Binatang & Bisa & Tidak Bisa \\
\hline & Ikan Paus & 10 & 2 \\
\hline & Ikan Hiu & 12 & 0 \\
\hline
\end{tabular}




\begin{tabular}{|c|c|c|c|}
\hline \multirow[t]{4}{*}{ No } & INDIKATOR & \multicolumn{2}{|c|}{ Jumlah Anak } \\
\hline & Ikan Koki & 12 & 0 \\
\hline & Lumba-lumba & 12 & 0 \\
\hline & Bintang laut & 10 & 2 \\
\hline \multirow[t]{7}{*}{4} & \multicolumn{3}{|c|}{$\begin{array}{l}\text { Jumlah Anak yang dapat menyebutkan ciri-ciri binatang dengan memilih salah satu } \\
\text { bagian tubuh dari binatang yang dipilih, dengan tujuan agar objek dapat mengeluarkan } \\
\text { suara dan menyebutkan nama bagian tubuh yang dipilih. }\end{array}$} \\
\hline & Nama Binatang & Bisa & Tidak Bisa \\
\hline & Ikan Paus & 12 & 0 \\
\hline & Ikan Hiu & 12 & 0 \\
\hline & Ikan Koki & 8 & 4 \\
\hline & Lumba-lumba & 12 & 0 \\
\hline & Bintang Laut & 12 & 0 \\
\hline \multirow{4}{*}{5.} & \multicolumn{3}{|c|}{$\begin{array}{c}\text { Setelah menggunakan augmented reality sebagai alat bantu belajar mengenal binatang, } \\
\text { anak lebih tertarik belajar mengenal binatang dengan... }\end{array}$} \\
\hline & Alat Peraga & & Tertarik \\
\hline & $\begin{array}{l}\text { APE (Alat Perag } \\
\text { Edukasi)/ Buku }\end{array}$ & & 0 \\
\hline & Augmented Realit & & 12 \\
\hline
\end{tabular}

Hasil uji coba menjelaskan bahwa $93 \%$ anak dapat mengenali objek binatang dari lingkungan hidupnya, sebesar $100 \%$ menyatakan anak dapat mengulang ejaan nama dari hewan dengan Bahasa Indonesia yang diperagakan dengan augmented reality, sebesar $95 \%$ anak dapat mengulang ejaan nama dari hewan dengan Bahasa Inggris yang diperagakan dengan augmented reality, sebesar 95\% anak dapat menyebutkan ciri-ciri binatang dengan memilih salah satu bagian tubuh dari bidanatang yag dipilih, dan sebesar 100\% menyatakan anak lebih tertarik menggunakan AR daripada menggunakan Alat Peraga Edukasi (APE) sebagai media pembelajaran.

\section{KESIMPULAN}

Berdasarkan analisa dan hasil pengujian yang telah dilakukan pada pembuatan media pembelajaran untuk memperkenalkan Binatang Berdasarkan Tempat Hidupnya untuk anak KB usia 3-4 Tahun Menggunakan Augmented Reality, maka dapat disimpulkan sebagai berikut :

1. Media Pembelajaran dapat menampilkan objek binatang secara 3D pada smartphone dengan menampilkan objek yaitu ayam, kuda, gajah, zebra dan sapi sebagai hewan yang hidup di darat dan objek objek ikan paus, bintang laut, ikan lumba-lumba, ikan hiu dan ikan koki sebagai hewan yang hidup di air.

2. Uji coba media pembelajaran disesuaikan dengan tujuan pembelajaran yang tertuang di kurikulum KBIT Wildani 2 Surabaya, yaitu: anak didik dapat menyebutkan nama binatang; anak didik dapat menyebutkan lingkungan tempat hidup binatang; anak didik dapat menceritakan kembali tentang ciri-ciri binatang yang didengar dan dilihatnya secara sederhana

3. Hasil uji coba menjelaskan bahwa 93\% anak dapat mengenali objek binatang dari lingkungan hidupnya, sebesar $100 \%$ menyatakan anak dapat mengulang ejaan nama dari hewan dengan Bahasa Indonesia yang diperagakan dengan augmented reality, sebesar 95\% anak dapat mengulang ejaan nama dari hewan dengan Bahasa Inggris yang diperagakan dengan augmented reality, sebesar 95\% anak dapat menyebutkan ciri-ciri 
binatang dengan memilih salah satu bagian tubuh dari bidanatang yag dipilih, dan sebesar $100 \%$ menyatakan anak lebih tertarik menggunakan AR daripada menggunakan Alat Peraga Edukasi (APE) sebagai media pembelajaran.

\section{DAFTAR PUSTAKA}

[1] Ruth Olmstead. Use of Auditory and Visual Stimulation to Improve Cognitive Abilities in Learning-Disabled Children. Journal of Neurotherapy, 9: 2, $49-61 \mathrm{pp}$. DOI: 10.1300/J184v09n02_04. 2010.

[2] Kementerian Pendidikan dan Kebudayaan Republik Indonesia (Kemdikbud RI). Undang-Undang Republik Indonesia Nomor 20 Tahun 2003 Tentang Sistem Pendidikan Nasional. 2003.

[3] Direktorat Pembinaan Taman Kanak-Kanak dan Sekolah Dasar (DikBin TK SD). Buku 3: Pedoman Pembelajaran Bidang Pengembangan Kognitif di Taman KanakKanak. Kementrian Pendidikan Nasional, Direktorat Jenderal Manajemen Pendidikan Dasar dan Menengah. Jakarta: Direktorat Pembinaan TK dan SD. 2007.

[4] Nixon D, Aldwinckle M. Exploring: Child Development from three to six years 2nd edition. Social Science Press, Katoomba. 2003

[5] Alach, H. Furry, feathered, finned or feral: Pets in early childhood settings. The First Years: Na Tau Tuatahi. New Zealand Journal of Infant and Toddler Education, 5(1), 25-27. 2003.

[6] Milgram, P., Kishino, F. Augmented Reality: A Class of Displays on the Realityvirtuality Continuum. In: SPIE Proceeding Telemanipulator and Telepresence Technologies, vol. 2351. 1994.

[7] Boud, A. C., Haniff, D. J., et al. 1999. Virtual reality and augmented reality as a training tool for assembly tasks. In Information Visualization, Proceedings. IEEE International Conference on, 19991999 (pp. 32-36). doi:10.1109/iv.1999.781532. 1999.

[8] M. Hincaoie., A. Caponio., H. Rios., and E. G. Mendivil, An Introduction to Augmented Reality with Applications in Aeronautical Maintenance, in ICTON. 2012.

[9] Barfield, W., Mann, S., Bair, K., Gemperle, F., et al. Computational Clothing and Accessories. In Fundamentals of Wearable Computers and Augmented Reality (eds. W. Barfield \& T. Caudell), Mahwan, NJ: Lawrence Erlbaum Associates. 2001.

[10] Hsieh, M.-C., \& Lee, J.-S. AR Marker Capacity Increasing for Kindergarten English Learning. Proceedings of the International MultiConference of Engineers and Computer Scientists IMECS 2008 Hong Kong, Vol. I. 2008.

[11] Rasslenda-Rass Rasalingam, Balakrishnan Muniandy, Rasslene Rass Rasalingam. Exploring the Application of Augmented Reality Technology in Early Childhood Classroom in Malaysia. IOSR Journal of Research \& Method in Education (IOSRJRME) e-ISSN: 2320-7388,p-ISSN: 2320-737X Volume 4, Issue 5 Ver. IV (Sep-Oct. 2014), PP 33-40. 2014

[12] Azfar Bin Tomia, Dayang Rohaya Awang Rambli. An Interactive Mobile Augmented Reality Magical Playbook: Learning Number With The Thirsty Crow. International Conference on Virtual and Augmented Reality in Education. Procedia Computer Science. 2013 